\title{
Sobre a Situação Energética Brasileira: De 1970 a 2030
}

On the Brazilian Energetic Situation 1970 - 2030

\begin{abstract}
Maria Thereza da Silva Lopes Lima ${ }^{1}$, Marina Corrêa de Souza ${ }^{2}$, Tarcísio Santos Flores ${ }^{3}$, Nathália Gracielle da Silva Cruz ${ }^{4}$, Hugo Duarte Diamantino ${ }^{5}$, Lívia Alves Barroso ${ }^{6}$, Bruna Almeida Rocha ${ }^{7}$, Rômulo Luiz Mendes Souza ${ }^{8}$, Pedro Camilo Ramos ${ }^{9}$ e Márcio Henrique Marques Macedo ${ }^{10}$

1,2, 3, 4, 5, 6, 7, 8,9 Graduandos em Engenharia Química do Instituto de Ciência e Tecnologia, UFVJM, Diamantina, Brasil.

${ }^{10}$ Graduando em Engenharia Mecânica do Instituto de Ciência e Tecnologia, UFVJM, Diamantina, Brasil.
\end{abstract}

\section{Resumo}

No presente trabalho relata-se, primeiramente, a situação energética brasileira a partir da grande crise petrolífera ocorrida na década de 1970. Na sequência, aborda-se o período compreendido entre as décadas de 1980 até 2005. Por fim, projeta-se cenários de um passado recente (de 2005 a 2013), do futuro que começa hoje e vai até 2030. Trata-se de um trabalho com fins educacionais, no qual provemos dados compilados para pesquisas escolares de todos os níveis.

Palavras-chave: Energética, projeção, matriz energética.

\begin{abstract}
In this paper we report, first, the Brazilian energy situation from the major oil crisis in the 1970s.Next, we discuss the period from the 1980s until 2005. Finally, it is projected scenarios from recent past (2005-2013), to the future that begins today and runs until 2030.This is a work for educational purposes, in which we provide compiled data for school research in all levels
\end{abstract}

Keywords: Energy, projection, energy matrix. 


\section{Introdução}

A ideia de produzir um trabalho como este surgiu de uma crença partilhada por muitos: a quantidade de energia de uma população está diretamente ligada ao seu desenvolvimento social. Ora, nós do Instituto de Ciência e Tecnologia (ICT) da Universidade Federal dos Vales do Jequitinhonha e Mucuri (UFVJM) estamos lotados numa das área mais pobres do Brasil. No norte de Minas Gerais há pequenos distritos que vivem de e com praticamente nada. Para esses, a era do extrativismo já terminou. A terra nada produz e a vida passa sem perspectivas. Muito além de fazermos caridades, é preciso investir na dignidade dessas populações, é preciso emprega-las, dar-lhes uma perspectiva justa. Porém, como proceder? Quem iria investir em um lugar seco, que nada dá? Mão-de-obra abundante e barata não atrai mais as grandes fábricas/indústrias. Então, o que as faria vir para cá? Energia abundante e quem sabe, subsidiada!

Por isso, resolvemos estudar a questão energética brasileira do ponto de vista histórico e criar este artigo/ relatório como um material de pesquisa para estudantes interessados em adquirir rapidamente uma visão geral, panorâmica da situação energética brasileira, a partir dos anos de 1970. Nossa ideia é simplesmente fazer com que os jovens pensem no assunto, sem os preconceitos imputados pela mídia desinformada. As forma de energia tem que ser vista em sua totalidade e não somente por um único aspecto, aquele que mais agrada ou interessa...

Por essas razões, construímos nosso trabalho de forma mais dinâmica, concentrando as fontes de dados numéricas em sua totalidade no final do trabalho.

Assim, iniciamos expondo o cenário energético atual do Brasil, com referência ao ano de 2012, segundo o Balanço Energético Nacional realizado pelo Ministério de Minas e Energia e a Empresa de Pesquisa Energética (2013), aponta para um consumo de $42,4 \%$ de energias renováveis, e 57,6\% de energia não renováveis, conforme $r$

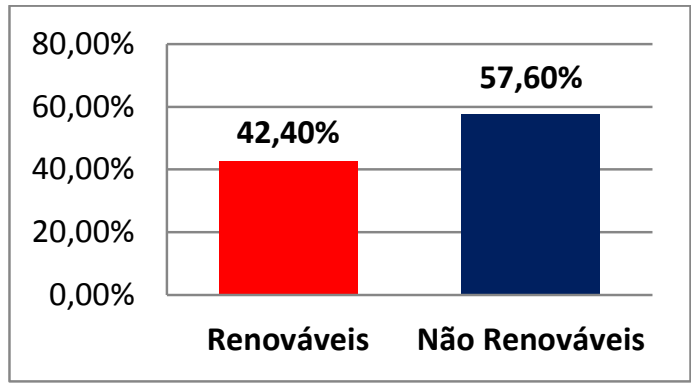

Figura 1 - Cenário energético do Brasil.

As energias renováveis incluem derivados de canade-açúcar - 15,4\%, hidráulica e eletricidade - 13,8\%, lenha e carvão vegetal - 9,1\%, lixívia e outras renová- veis $-4,1 \%$ e as energias não renováveis incluem o gás natural $-11,5 \%$, carvão mineral e seus derivados $-5,4 \%$, petróleo e derivados - 39,2\% e urânio e derivados - 1,5\%. A Tabela 1 faz um comparativo entre as principais fontes não renováveis, apresentada em anexo, com o nome de Tabela 1 Suplementar.

O consumo total de energia em 2012 foi de 283,6 milhões de tep. A oferta interna de energia (total de energia demandada no país) aumentou 11,3 mi-lhões de toneladas equivalentes de petróleo (Mtep), anotando uma taxa de crescimento de 4,1\% e atingindo 283,6 Mtep.

O gás natural, o petróleo e os derivados responderam por $97 \%$ deste incremento. Isto ocorreu basica $\neg$ mente através da redução na oferta interna de biomassa da cana, notadamente do etanol, e de hidroeletricidade. Uma vez que a produção de derivados, ainda que tenha aumentado, não acompanhou o ritmo da demanda, houve, como consequência, maior importação de gasolina e diesel. Outro reflexo foi a redução da proporção de renováveis na matriz energética. Contudo, essa participação manteve-se em patamar muito elevado, de 42,4\%, significativamente acima da média mundial, calculada em 13,2\% pela Agência Internacional de Energia.

Entre todos os setores demandantes de energia, o segmento de transporte foi o que liderou o crescimento da demanda. O consumo agregado do setor, envolvendo transporte de carga e de pessoas, cresceu à expressiva taxa de 7,2\%. No transporte de carga, o licenciamento, entre 2011 e 2012, de mais de 312 mil novos caminhões figuram entre os elementos que explicam o crescimento de $6,1 \%$ no consumo de óleo diesel. Complementando o quadro do setor de transporte, registra-se o crescimento de $5,4 \%$ no consumo de querosene de aviação.

No setor de energia elétrica, apesar do aumento de 1.835 MW na potência instalada do parque hidroelétrico, a oferta de energia hidráulica reduziu-se em 1,9\% devido às condições hidrológicas observadas em 2012, especialmente na segunda metade do ano. A menor oferta hídrica explica o recuo da participação de renováveis na matriz elétrica, de 88,9\% em 2011 para $84,5 \%$ em 2012. A potência eólica atingiu $1.894 \mathrm{MW}$, o que proporcionou uma geração que praticamente dobrou a fatia desta fonte na matriz elétrica nacional. $\mathrm{O}$ aumento do consumo final de eletricidade, de 3,8\%, puxado pelas famílias e pelo setor de serviços, foi atendi-do com aumento da geração térmica convencional, especialmente das usinas movidas a gás natural, cuja participação na matriz cresceu de $4,4 \%$ para $7,9 \%$. Como decorrência houve aumento das perdas na transformação (o rendimento da planta térmica na conversão para eletricidade é bastante inferior ao da usina hidroelétrica).

No período entre 1970 e 2004 ocorreram significativas mudanças na matriz energética nacional. A mais acentuada foi a perda de participação da lenha que representava 46\% do consumo final no país em 1970. De principal fonte energética utilizada, sua participação passou a representar apenas 8\% no ano de 2004. 
Outros produtos, tais como bagaço de cana, derivados de petróleo e gás natural, por outro lado, apresentaram fortes crescimentos nas suas participações relativas. A Tabela 2 apresenta a evolução do consumo final por fonte entre os anos selecionados, anexada como Tabela 2 Suplementar.

Conforme pode ser observado, o consumo final no país passou de $62.106 \mathrm{ktep} \mathrm{em} 1970$ para $191.128 \mathrm{ktep}$ em 2004. Um aumento de $207,7 \%$ em 34 anos, representando um crescimento médio de 3,4\% a.a.; e também pode ser observado, no caso dos derivados de petróleo, o consumo em 1970 era de $23.510 \mathrm{ktep}$, equivalente a cerca de $38 \%$ do consumo final. Ao longo do período, o consumo destes produtos aumentou aproximadamente $252 \%$, chegando a $43 \%$ do consumo final em 2004. Este crescimento não foi uniforme ao longo do tempo. O principal fato para que isto ocorresse foi a crise de preços do petróleo no mercado internacional ao longo da década de 1970. Isto contribuiu para que o consumo apresentasse uma queda acentuada após o final da referida década e o início dos anos 1980, pois o país era fortemente importador de petróleo. Em 1979, os derivados atingiram um pico de $53 \%$ de participação no consumo final no Brasil, apresentando um comportamento declinante até 1985, com $41 \%$. A partir deste período, a participação voltou a crescer até o final da década de 1990 e, mais uma vez, apresentou queda na participação após esse período.

Analisando os derivados individualmente, é possível observar que os consumos finais de alguns efetivamente apresentam reduções ao longo do período analisado. É fato, por exemplo, que ainda em 2004 o consumo de óleo combustível encontra-se inferior ao valor observado em 1970. Nesse ano, o consumo desse energético foi equivalente a $6.600 \mathrm{ktep}$, representando $9 \%$ do consumo final do país. Em 2004 o consumo foi 3\% inferior a este valor, cerca de $6.431 \mathrm{ktep}$, com uma participação de apenas 3\%.

Já o consumo de gás natural no país foi muito reduzido ao longo da década de 1970. Neste período, ainda, não havia importação de gás. Além disso, no caso brasileiro, o gás natural ocorre, principalmente, associado ao petróleo. A produção nacional deste ainda era pequena na época, contribuindo ainda mais para a baixa disponibilidade de gás. Além disso, em função de não existir uma demanda própria que viabilizasse a comercialização, parte do gás existente era injetada novamente nos poços ou queimado nas plataformas.

Conforme mostrado nas Figuras 2, 3, 4, 5 e 6 observa-se um primeiro aumento significativo do consumo a partir do início da década de 1980 e um segundo somente a partir do final dos anos 1990 . O primeiro aumento ocorreu, principalmente, em função da descoberta e início de operação de algumas jazidas localizadas na Bacia de Campos, associado à produção de petróleo. $\mathrm{O}$ aumento do consumo de gás natural, em parte, ocorreu pelo incremento da produção nacional de petróleo, como gás associado. O segundo aumento, por sua vez, ocorreu somente no final dos anos 1990, mais especificamente em 1999, com o início da primeira etapa da operação do gasoduto Brasil-Bolívia.

Neste contexto, em todo o período analisado, entre 1970 a 2004, o consumo final de gás natural cresceu expressivos $17.215 \%$, ou seja, um crescimento médio de $16,4 \%$ a.a.. A magnitude destes números reflete principalmente os baixos valores no início do período analisado, pois em 1970 o consumo final deste energético era de apenas 70 ktep. No ano de 2004, o consumo chegou a $12.185 \mathrm{ktep}$. Sua participação, de praticamente inexistente em 1970, passou a representar 6\% do consumo final em 2004.

Algumas análises complementares comprovam que a hidroeletricidade ainda é a opção natural do Brasil mesmo diante de barreiras ambientais cada vez mais restritivas aos aproveitamentos dos potenciais hidráulicos. De fato, tem sido crescente a dificuldade de licenciamento ambiental para novos empreendimentos hidroelétricos. Tal fato tem sido acompanhado de uma expansão notável da geração termelétrica.

A geração de eletricidade a partir de usinas termelétricas, além de contribuir para mitigação dos riscos hidrológicos pela diversificação, conta também com a vantagem de localização próxima aos centros consumidores, diminuindo a necessidade de investimentos em transmissão. Desta forma, em 2004, a capacidade instalada de termelétricas no país já se apresentava bem distribuída em todas as regiões.

\section{A Evolução do Consumo Final no País}

A estrutura de consumo de energia no país sofreu variações significativas entre 1970 e 2004 . Os processos de industrialização e urbanização, os ciclos de crescimento e os períodos de estagnação econômica, e as facilidades de utilização que alguns energéticos apresentam em relação a outros, provocaram alterações no consumo e nas participações relativas dos energéticos no consumo final.

Analisando as estruturas de consumo nos anos de 1970 e 2004 como seções transversais no tempo, é possível identificar as principais alterações ocorridas. Conforme podemos observar em nossos estudos, em 1970, a lenha $46 \%$ do consumo final do país, sendo o principal energético utilizado. A representativa parcela da população que residia no campo contribuía para este elevado consumo, assim como seu baixo rendimento no uso, demandando quantidades elevadas de energia final para o atendimento dos requisitos de energia útil.

A participação dos derivados de petróleo no ano já era elevada: $38 \%$. Gasolina, óleo combustível e diesel eram os mais utilizados, com participações de $12 \%, 11 \%$ e 9\%, respectivamente. Estes três, mais a lenha, representavam aproximadamente $78 \%$ do consumo final do país. Os demais energéticos apresentavam utilização ainda reduzida. A energia elétrica e o bagaço, por exemplo, ainda participavam com apenas $5 \%$ do consumo cada. 
A participação do gás liquefeito de petróleo, GLP, era ainda menor: cerca de $2 \%$ do consumo final.

Em vista do que pudemos conferir, em 2004, a lenha deixou de ser o energético mais utilizado para representar apenas $8 \%$ do consumo final. Os derivados de petróleo passaram a apresentar uma participação pouco superior, de $38 \%$ para $43 \%$. O consumo de gás natural, de quase inexistente em 1970, atingiu uma participação de $6 \%$ em 2004. De forma equivalente, as participações da energia elétrica e do bagaço cresceram fortemente no período, atingindo $16 \%$ e $11 \%$, respectivamente.

\section{Capacidade Instalada}

A capacidade instalada de geração de energia elétrica em centrais elétricas autoprodutoras, de acordo com site da ANEEL são empresas que produzem energia elétrica para seu uso exclusivo, atingiu os 6.630 MW em 2004, representando $7,3 \%$ da capacidade instalada de geração de energia elétrica do país. Destes, 5.200 MW são em centrais termoelétricas, equivalente a $23,9 \%$ da capacidade instalada de geração em centrais termoelétricas, e 1.430 MW em centrais hidroelétricas, equivalente a $2,3 \%$ da capacidade instalada de geração em centrais hidroelétricas.

Enquanto a capacidade instalada de geração de energia elétrica total cresceu 4,7\% entre 2003 e 2004, passando de $86,51 \mathrm{GW}$ para $90,73 \mathrm{GW}$, a capacidade instalada de geração de energia elétrica em centrais elétricas autoprodutoras cresceu $6,5 \%$, passando de 6,22 GW para $6,63 \mathrm{GW}$. A pesquisa mostra que a capacidade instalada em usinas hidroelétricas cresce a uma taxa quase que constante ao longo das últimas duas décadas. A partir do final da década de 1980, o aumento da capacidade instalada para geração termoelétrica convencional e nuclear refletem a diversificação da matriz energética brasileira.

Fazendo uma breve análise comparativa ao longo das três últimas décadas, antecedentes a 2003, permitindo uma visão ampla da evolução da matriz energética brasileira foi possível observar que nesse contexto ocorreu:

a) Um aumento de produção primária de energia, viabilizando o processo de retomada do crescimento econômico;

b) Uma redução do consumo de lenha, com a diversificação da matriz energética;

c) Um aumento do consumo do gás natural, seguindo uma tendência mundial de expansão desse energético;

d) Uma expansão do consumo da biomassa em todos os setores;

e) Um aumento do consumo de eletricidade e do consumo per capita, justificada pela universalização e pelo crescimento econômico;

f) Uma manutenção da predominância da geração hidroelétrica na capacidade instalada para geração de energia elétrica; g) Uma expansão da capacidade instalada de termelétrica, favorecendo a mitigação dos riscos hidrológicos;

h) Uma redução da dependência externa de energia, principalmente do petróleo;

Finalmente, observa-se que o Brasil segue a maioria das tendências mundiais na evolução da oferta e do consumo energético, sem deixar de valorizar suas potencialidades e suas vantagens comparativas, como acontece, por exemplo, com a utilização da biomassa, na qual o Brasil posiciona-se como referência mundial.

\section{Energia Elétrica do Brasil no Período de 1980 até 2005}

A produção primária de energia no período de 1980 a 2005, mostra dois períodos de forte crescimento: na primeira metade da década de 1980, resultante do processo de industrialização e a partir da segunda década de 1990, levando em consideração o fator do forte crescimento da produção de petróleo.

A análise da produção primária de energia recente tem chamado atenção para a evolução da autoprodução de energia elétrica.

O crescimento da autoprodução de energia elétrica nos dez anos entre 1994 e 2004 significou uma taxa média de crescimento de $13,1 \%$ a.a.. As fontes primárias utilizadas nas centrais elétricas de autoprodução que apresentaram maior crescimento no período destes 10 anos foram o gás natural, com taxa média de crescimento de $25,3 \%$ a.a., e a energia hidráulica, com taxa média de crescimento de $14,2 \%$ a.a.. Destacam-se ainda o crescimento da biomassa, em particular o bagaço de cana, e dos gases industriais.

Neste contexto econômico, a oferta interna de energia aumentou 5,7\% em 2004, passando de 201,9 Mtep para 213,4 Mtep e, o consumo final de energia passou de 182,1 Mtep para 191,1 Mtep, o que representa um crescimento no ano de $4,9 \%$.

Do lado do consumo, os derivados de petróleo apresentam maior crescimento nas últimas três décadas, intensificado dos anos 1980, como pode ser observado na Figura 2.

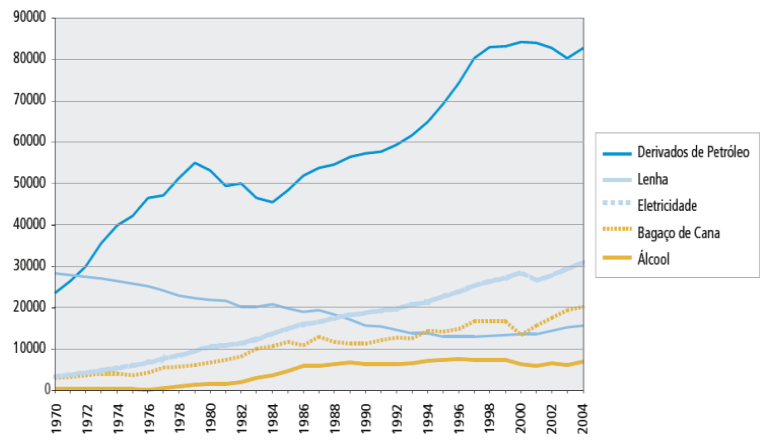

Figura 2 - Consumo final por fonte (103 tep). 
Eletricidade e bagaço de cana também apresentaram crescimento ao longo de praticamente todo o período analisado, excetuando-se o período do racionamento de energia elétrica em 2001. O consumo de álcool embora em taxas mais modestas também apresenta crescimento.

A análise do consumo por fonte mostra que o consumo energético é dominado pelos derivados de petróleo. Os consumos de eletricidade e bagaço de cana tem apresentado um ligeiro aumento na sua participação. Observa-se ainda uma redução significativa no consumo de lenha até meados da década de 1990, e uma estabilização da participação da lenha de 1995 em diante.

Em 2004, o agregado derivados de petróleo apresentou um crescimento de apenas 2,3\%, em boa parte devido a redução do consumo final de óleo combustível, de $-11,0 \%$, já que os consumos de gasolina, óleo diesel e querosene de aviação apresentaram, respectivamente, crescimentos de $3,7 \%, 6,2 \%$ e $7,4 \%$. O consumo de eletricidade cresceu $5,1 \%$ no agregado, com destaque para o setor industrial. Os grandes destaques são o etanol e o gás natural que cresceram $11,6 \%$ e $21,5 \%$, respectivamente, com expansão nos setores transporte e industrial.

Esse consumo concentra-se principalmente nos setores industrial e transportes que apresentam as maiores taxas de crescimento desde 1970.

O setor industrial em 2004 atinge 40\% de participação do consumo total de energia no país. Em relação a 2003, o consumo de energia no setor industrial aumentou de 68,4 Mtep para 72,2 Mtep, representando um aumento de 5,3\%, conforme pode ser visto na Figura 3.

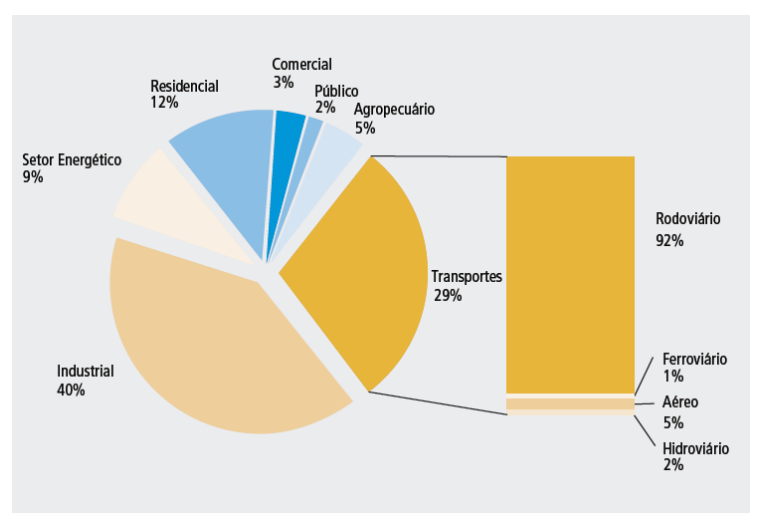

Figura 3 - Evolução do consumo final de energia por setor.

O consumo de energia elétrica cresceu 7,1\% neste setor no período, elevando sua participação no total do setor industrial de $20,2 \%$ para $20,5 \%$. O consumo de carvão mineral do setor industrial representa $96 \%$ do consumo final desta fonte, e cresceu 4,6\% em 2004, entretanto, sua participação caiu de $16,1 \%$ para $9 \%$ no total do setor.

$\mathrm{O}$ consumo pelo setor industrial de biomassa (que inclui lenha, lixívia, carvão vegetal, produtos da cana-de -açúcar (bagaço e álcool etílico), outros resíduos vegetais e outras fontes renováveis), cresceu $8,4 \%$ no ano 2004 , elevando sua participação de 37,9\% para 38,9\% do total do setor industrial.

A abertura dos setores industriais em 2004, destaca os principais setores energéticos no Brasil: ferro-gusa e aço, alimentos e bebidas, papel e celulose, química e não ferrosos. Analisando a evolução nos últimos 30 anos, observa-se que houve uma redução da participação dos setores de alimentos e bebidas, cimento e cerâmica no consumo energético do setor industrial. Em contra partida os setores de ferro-gusa e aço, mineração, papel e celulose e não ferrosos e outros metais ganharam participação.

O setor de transportes, responsável por $29 \%$ do consumo é dominado pelo transporte rodoviário que representa $92 \%$ do consumo do setor de transportes.

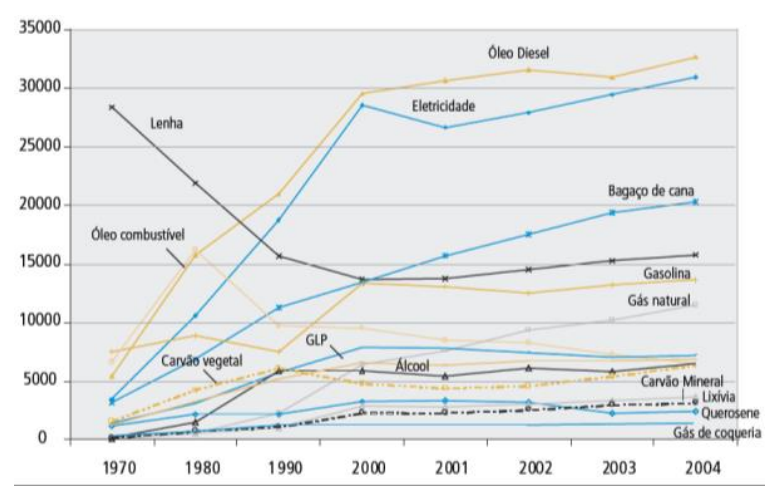

Figura 4 - Evolução de consumo final energético por fonte (tep).

A Figura 4 apresenta a evolução do consumo final energético por fonte, realçando o forte crescimento nos consumos de óleo diesel e eletricidade nas três últimas décadas. Fica claro o processo de substituição da lenha que decresce de 1970 a 2000.

Observa-se também a recente substituição do óleo combustível por gás natural, responsável pelas maiores taxas de crescimento de 2002 a 2004.

$\mathrm{Na}$ análise do consumo de eletricidade, observa-se que houve queda na participação dos setores energéticos e transportes de 1970 a 2005. Em contrapartida o setor agropecuário aumenta sua participação a partir de 2000. Os setores públicos e comerciais mantêm sua participação praticamente estável no horizonte analisado.

O setor residencial que crescia sua participação de 1970 a 2000, sofreu os impactos do racionamento e apenas em 2004 recupera a participação da década de 1970. Com isso, o consumo de energia elétrica da classe residencial passou de 76,1 TWh em 2003 para 78,6 TWh em 2004, um crescimento de $3,2 \%$, todos os fatores acima apresentados estão evidenciados na Tabela 3 Suplementar em anexo.

Estes resultados refletem a combinação de fatores como o processo de substituição do gás manufaturado 
nas redes das concessionárias de distribuição canalizada e a expansão destas mesmas, alcançando consumidores antes atendidos pelo GLP.

Como resultado dos esforços de universalização do atendimento de energia elétrica, verifica-se no período entre 2000 e 2004, e no biênio 2003/2004, reduções no consumo de querosene pela classe residencial de $-63,6 \%$ e $5,9 \%$, respectivamente.

O consumo final dos derivados de petróleo vem perdendo participação nos setores industrial e residencial, queda que vem sendo compensada pelo aumento da participação dos setores energético e agropecuário. $\mathrm{O}$ setor de transportes, responsável por metade do consumo dos derivados de petróleo mantém sua participação relativamente estável em 2004, tendo apresentado queda significativa a partir da década de 1980, em função do segundo choque do petróleo e do Proálcool, que deslocou parte do consumo de gasolina.

A intensidade energética refere-se ao montante de energia consumido em tep para gerar 1000 US\$ de PIB. A Figura 5 demonstra a evolução da intensidade energética no Brasil nas últimas três décadas para os principais setores energéticos.

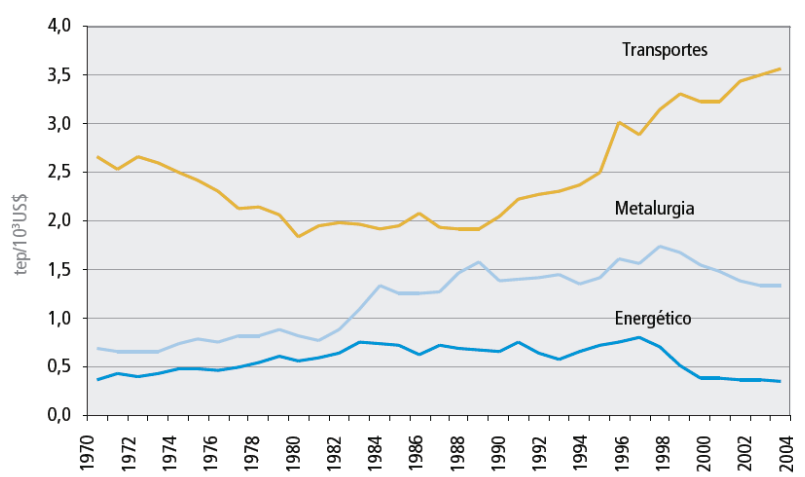

Figura 5 - Intensidade energética dos setores transportes, metalúrgica e energética.

Na Figura 5, destaca-se o setor de transportes, o mais energético dentre os analisados no Balanço Energético Nacional (BEN) que apresenta uma trajetória crescente, em particular no início da década de 1990. A partir de meados de 1990 a intensidade energética do setor de transportes supera 2,5 tep/103 US\$, chegando em 2004, com uma intensidade energética que ultrapassa 3,5 tep/103 US\$.

O setor metalúrgico atinge a sua intensidade mais alta no final da década de 1990 e já aponta para uma tendência de estabilidade inferior a 1,4 tep/103 US\$ em 2004. O mesmo acontece com o setor energético que estabiliza a partir de 2000 em torno de 0,35 tep/103 US\$.

Alguns principais indicadores permitem analisar e calcular a evolução do setor energético, paralelamente à evolução de indicadores socioeconômicos. O primeiro desses indicadores é a oferta interna de energia/ população.

Outro indicador que pode ser acompanhado é o consumo por habitante. A Figura 6 apresenta a evolução do consumo de eletricidade, total e consumo na cocção por habitante nas últimas três décadas.

Observa-se que o consumo de eletricidade per capita é crescente até 2001 quando houve o racionamento de energia elétrica. Passada a crise, o consumo volta a crescer em 2003. No entanto, em 2004 o consumo de 0,433 MWh/ hab ainda é próximo ao consumo per capita verificado do ano de 1996 (0,428 MWh/hab).

A oferta interna de energia é definida como a quantidade de energia que se disponibiliza para ser transformada e/ou para consumo final. Expressa a energia antes dos processos de transformação e de distribuição

A oferta de energia per capita, representada uma tendência de crescimento suave chegando a 2004 com 1,175 tep/hab. A última queda observada nesse indicador foi de 1989 para 1990 quando a oferta interna de energia passou de 1,019 para 0,969. O patamar de 1989 somente foi recuperado em 1995.

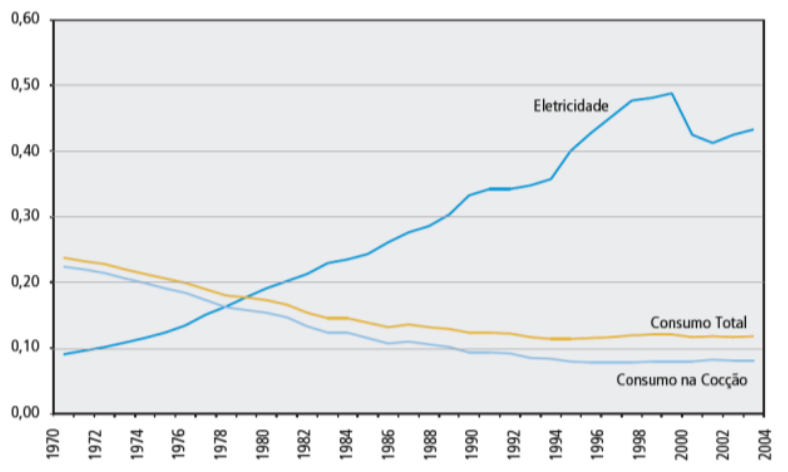

Figura 6: Evolução do consumo per capta.

Por volta de 1970, devido às crises do petróleo, a busca de alternativas para a geração de energia era grande, o que levou a energia nuclear ser vista como uma alternativa promissora. Recendendo atenção de analistas e empreendedores, em pouco mais de duas décadas, a energia nuclear aumentou $17 \%$ na produção mundial de energia elétrica.

Considerando os avanços do setor nuclear, o governo brasileiro começou a elaborar, no fim da década de 1960, o Programa Nacional Brasileiro destinado a implantar no país produção de energia atômica. O Plano executado pela Nuclebras (empresa criada em 1974 voltada para esse fim), tinha como instalar oito usinas nucleares no país até 1990 .

Angra I foi a primeira usina nuclear a entrar em funcionamento. Com potência de $625 \mathrm{MW}$, a usina começou a funcionar em 1981, mas foi paralisada em seguida por 
problemas técnicos, voltou a funcionar apenas em 1983 e ainda assim sem operação permanente com capacidade total. De acordo com o Programa Nacional Brasileiro, as usinas Angra II e Angra III deveriam entrar em funcionamento em 1983 e 1984, respectivamente, mas Angra II só entrou em operação em 2000 e Angra III ainda nem está em funcionamento.

O avanço da geração de energia elétrica provida do urânio, no Brasil, de 1990 até 2005 é notória, com destaque em 2004 e em 2002.

De 1990 até 1999 obtinha-se 0,0\% de produção, a partir daí a produção foi aumentando. Em 2000, tinha 0,1\%, em 2001 produziu 0,4\%, em 2002 obteve 1,9\%, 2003 1,5\%, em 2004 1,9\% e por fim em 2005 houve uma queda para $0,7 \%$.

A evolução da oferta interna de energia também teve números favoráveis, em 1990 obtinha-se 0,4\% e em 2005 teve um aumento para 1,2\%. Nesse período podemos destacar os anos de 2001, 2002, 2003, em que teve um percentual de $2,0 \%, 1,9 \%$ e $1,8 \%$, respectivamente.

A oferta e a geração de energia nuclear no Brasil ainda é baixa se compararmos com a geração de energia por outras fontes, principalmente do petróleo e do álcool que deve ser bem estudado e trabalhado para que possamos mudar essa situação.

\section{Projeções do Cenário Energético Brasileiro}

Nas últimas décadas, o Brasil experimentou um processo de intensas mudanças em sua economia e na estrutura de sua produção de energia para poder suprir a demanda energética crescente.

Baseando-se nas projeções de crescimento dos próximos anos tendo como base o ano de 2005 o Ministério de Minas e Energia (MME) criou e divulgou o Plano Nacional de Energia 2030, que fornece a formulação de estratégias para a ampliação da oferta de energia capaz de suprir a demanda até o ano de 2030.

Como tal trabalho refere-se a um processo de previsão do cenário brasileiro as diversas considerações utilizadas levaram a criação de quatro diferentes perspectivas sobre a projeção do consumo final de energia. Portanto, o Plano Nacional de Energia leva em consideração não só o consumo de energia elétrica, já que o consumo final de energia leva em consideração toda energia que atende as necessidades da sociedade de um modo geral, tais como o transporte, a indústria e o comércio.

O Plano 2030 foi desenvolvido para quatro trajetórias distintas, apesar das diversas considerações avaliadas durante o processo de formulação, o plano avaliou principalmente as projeções sobre a economia, sendo que os cenários A, B1, B2 e C são associados ao crescimento de $5,1 \%, 4,1 \%, 3,2 \%$ e $2,2 \%$, respectivamente do crescimento do PIB no período compreendido entre o ano de 2005 e 2030. Apesar da construção dos diversos cenários, o

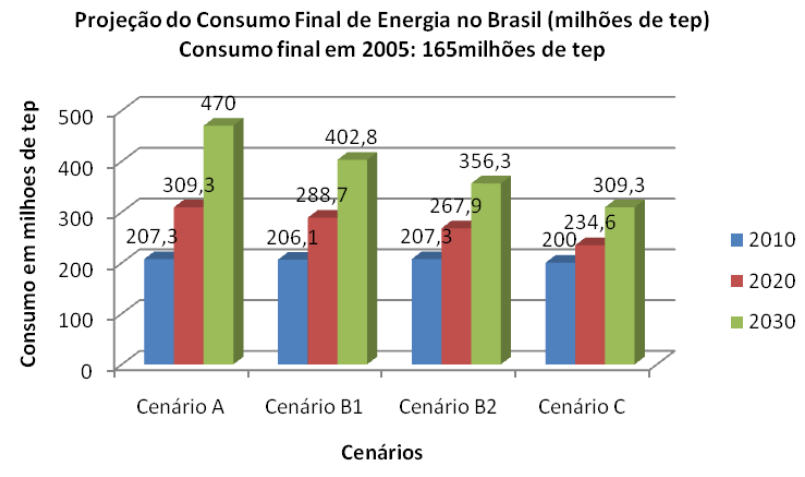

Figura 7 - Projeções do consumo final de energia por cenário realizada pelo MME.

cenário B1 foi priorizado para o estabelecimento das estratégias energéticas desenvolvidas pelo governo.

O cenário B1 prevê uma ampliação na diversificação da matriz energética no período de 2005/2030, ainda de acordo com as projeções deste cenário, ocorrerá uma redução significativa do uso do carvão vegetal e da lenha, de $13 \%$ para apenas 5,5\%. Por outro lado, ocorreria um aumento da participação do gás natural, que passaria de $9,4 \%$ para $15,5 \%$; e um crescimento no uso também de fontes energéticas procedentes da canade-açúcar, como por exemplo, o etanol e outras fontes renováveis tais como o biodiesel e o H-bio que passaria de uma participação de $16,7 \%$ para $27,6 \%$. Sendo que este aumento significativo da participação de fontes renováveis decorreria da redução da participação do petróleo e seus derivados, principalmente no setor de transporte, de $38,7 \%$ para $28 \%$.

Sabendo-se que uma das maiores preocupações no âmbito de suprir as necessidades energéticas está relacionada com a demanda de energia elétrica, o cenário base do Plano estima que em 2030 o consumo total de energia elétrica será da ordem de 1.083,4 TWh, desta forma fornece a formulação de estratégias para a ampliação da oferta de energia capaz de suprir a demanda até o ano de 2030.

De acordo com as estratégias traçadas a hidroeletricidade se manterá predominante até 2030 devido principalmente a competitividade econômica com as termoelétricas, sendo assim o Brasil que possui uma capacidade aproveitável de instalação de 174 GW deverá aproveitar até 2030 cerca de $94 \%$ do montante disponibilizado, ou seja, 164 GW. Porém, tal aproveitamento implica em enfrentar diversos desafios ambientais já que a maior parte dos recursos ainda disponíveis para o aproveitamento encontra-se na Amazônia legal.

Analisando a projeção da demanda de eletricidade notou-se a necessidade de ampliar a quantidade de usinas termoelétricas prioritariamente na base, a fim de complementar a geração de energia. A ênfase está 
voltada para o uso de carvão mineral, da energia nuclear e da biomassa. Sendo assim, devido a ampliação o carvão mineral deve evoluir de $2 \%$ para $3 \%$ e a energia nuclear deve evoluir $3 \%$ para $5 \%$ na oferta de eletricidade entre 2005 e 2030. A biomassa também apresentará um aumento na participação na matriz energética já que se trata de uma excelente opção, pois é competitiva e ambientalmente viável.

Outras alternativas também se encontram na composição das estratégias para a geração de energia elétrica nos próximos anos. A principal aposta do governo são as PCH's, ou seja, as pequenas centrais hidroelétricas que possuem capacidade instalada superior a $1 \mathrm{MW}$ e inferior ou igual a $30 \mathrm{MW}$ além de possuírem área menor que $13 \mathrm{Km}^{2}$.

Apesar dos estudos indicarem que o cenário B1 era o mais possível de ocorrer, nem este ou mesmo o cenário mais otimista (cenário A) projetado em 2005 foi capaz de prever um crescimento tão acelerado do consumo energético final no país. De acordo com Balanço Nacional Energético de 2013 a expectativa de consumo foi atingida e ultrapassada bem antes do que se esperava, em $2007 \mathrm{o}$ consumo já tinha atingindo a marca de 215.197 ktep, ou seja, já havia ultrapassado a marca máxima prevista de aproximadamente 207,3 ktep no ano de 2010.

Nesse contexto, o MME está desenvolvendo um novo plano, o Plano Nacional de Energia 2050, que abordará de forma atualizada os desafios que o país terá que enfrentar para suprir a demanda crescente de energia. Segundo o secretário de Planejamento e Desenvolvimento do Ministério de Minas e Energia Altino Ventura Filho, o Brasil passará a ter as usinas nucleares, a carvão mineral e a gás natural na base para garantir o fornecimento de energia elétrica.

As usinas termoelétricas nas próximas décadas deixarão de apenas auxiliar e passarão a compor a base do fornecimento contínuo de energia elétrica, já que na próxima década as hidroelétricas terão seu potencial quase que completamente esgotado. As térmicas também serão auxiliadas pelas fontes renováveis, tais como, eólica, solar e biomassa.

Apesar do MME não ter se pronunciado a respeito da configuração da matriz energética que atende a demanda total de energia, ou seja, toda e qualquer forma de energia que atende as necessidades da sociedade é de se esperar que o petróleo e seus derivados continuem constituindo uma das principais fontes de energia apesar de seu decaimento contínuo que dá espaço a fontes energéticas alternativas e renováveis como os biocombustíveis.

\section{A Energia a Partir de 2005 até 2030}

A demanda energética de um país está fortemente correlacionada com sua atividade econômica, ou seja, o Produto Interno Bruto. A medida dessa correlação é dada através da intensidade energética do país.
No caso específico do Brasil, a correlação entre consumo energético e crescimento econômico é de 0,82 de acordo com os dados entre 1970 e 2004 da análise energética do Ministério de Minas e Energia.

No período compreendido entre as últimas quatro décadas, o consumo final de energia no Brasil cresceu a razão de 3,0\% ao ano e apresentou importantes alterações estruturais. No ano de 1970, a principal fonte energética era a lenha, representando $48 \%$ das necessidades brasileiras no uso final de energia. O petróleo, no mesmo ano, já representava $36 \%$ da demanda. Entre 1970 e 1990, o consumo de lenha reduziu para uma taxa de 2,9\% ao ano. Com a crise energética dos anos 1970, o Brasil investiu nas fontes energéticas hidráulicas e de cana-de-açúcar, que tiveram um ritmo de crescimento de 6,6\% ao ano, entre os anos de 1970 e 2005.

Atualmente, o petróleo predomina na matriz energética com $41 \%$ de participação e a eletricidade é a segunda forma mais utilizada, com 19\%. Com a inserção do etanol na matriz, através da adição à gasolina e mais recentemente com a popularização dos veículos flexfuel, a cana-de-açúcar representa $12 \%$ de participação na matriz energética nacional.

Devido o Brasil se encontrar em um período de desenvolvimento econômico robusto, existe um processo de mudanças na sua estrutura econômica e de produção de energia. Em 2006, o país inverteu a balança de importação de petróleo e hoje tem a possibilidade de se tornar um grande produtor de petróleo e gás natural com atuação internacional. Segundo dados da Agência Nacional de Petróleo, de uma reserva nacional total aproximada de 16 bilhões de barris em 2005, onde 91,6\% se localiza no mar (campos "off shore"), e o restante localizado em campos terrestres. Considera-se como reserva total o somatório de reservas provadas, prováveis e possíveis. Já em relação ao gás-natural, cerca de $75 \%$ das reservas brasileiras de gás natural se localiza em campos "off-shore" e $25 \%$ em campos terrestres (campos "on shore").

Além de um enorme potencial na produção de combustíveis fósseis, o Brasil faz parte do grupo de países em que a produção de eletricidade é proveniente, na sua maior parte, de usinas hidroelétricas. Essas usinas correspondem a $75 \%$ da potência instalada no país e geraram, em 2005, 93\% da energia elétrica requerida no Sistema Interligado Nacional - SNI, sendo que ainda há uma parcela significativa de potencial a ser aproveitado.

O Brasil também possui um grande potencial de exploração de urânio para utilização em novas usinas nucleares. No entanto, o processo é mais complexo devido às questões ambientais, altos custos de investimento e a importação de tecnologia, atrasando, dessa forma, a construção de novas usinas nucleares.

\subsection{Petróleo}

O país tornou-se auto-suficiente em petróleo e no final de 2007, as reservas provadas de petróleo no Brasil 
estavam estimadas em 11,41 bilhões de barris. Sabendo que a taxa de crescimento das reservas brasileiras desde 1980 girou em torno de $9 \%$ ao ano, estima-se que a taxa de crescimento de reservas se manterá em $9 \%$ a partir de 2009 e à medida que as descobertas são realizadas, essa taxa decrescerá em $0,5 \%$ ao ano. Além da taxa de crescimento das reservas, também são contabilizadas as reservas especulativas F95, baseadas em um critério de probabilidade definido pela U.S. Geological Survey a qual segue a seguinte classificação:

a) Reservas F95: Probabilidade de 95\% de exploração. No caso brasileiro, são as reservas decorrentes de compromissos assumidos entre a ANP e o concessionário e de minuciosos projetos de produção.

b) Reservas F50: Probabilidade de 50\% de confirmação da reservas, estimativas baseadas em estudos geológicos.

c) Reservas F5: Probabilidade de 5\% de confirmação das reservas, com base em estudos geológicos e especulação.

Somente as reservas F95 como passíveis de exploração que somam 8.060 milhões de barris. Dada a complexidade de exploração e produção e os custos envolvidos, estimase que tais reservas possam ser definidas como reservas provadas com início de utilização a partir de 2020, sendo $24 \%$ em 2020, 46\% em 2025 e os 30\% restantes em 2030. Ainda que a produção do petróleo seja decadente, os picos devem-se ao descobrimento de novas reservas F95 e ao desenvolvimento na tecnologia de refinaria.

\subsection{Gás Natural}

As perspectivas de oferta de gás natural no Brasil se concentram com grande potencial na bacia de Campos e na Bacia de Santos. A Petrobrás e seus parceiros, de acordo com seu plano diretor, prometem investir cerca de R 18 bilhões nos próximos 10 anos na exploração e produção na Bacia de Santos, que em curto prazo prevê um acréscimo de 12 milhões de m3/dia no fornecimento de gás natural até o final de 2008. Até o final de 2010, a projeção é de aumentar a produção acrescentando 30 milhões de m3/dia o que diminuirá a dependência do Brasil em gás importado.

O Plano de negócios Petrobrás 2007-2011 projeta que as reservas de gás natural de 2006 a 2030 terão um crescimento aproximadamente linear dado pela Tabela 1.

Tabela 1 - Projeção de reserva de gás natural.

\begin{tabular}{|c|c|}
\hline Ano & Reservas (bilhões de $\mathbf{~ m}^{\mathbf{3}}$ ) \\
\hline 2005 & 306 \\
\hline 2010 & 631 \\
\hline 2020 & 1110 \\
\hline 2030 & 1650 \\
\hline
\end{tabular}

Em relação ao consumo de gás natural no Brasil, esse tem crescido a uma taxa de $10,3 \%$ ao ano. A indústria e o setor energético foram os maiores responsáveis por este crescimento. O setor de transportes também influenciou no aumento da demanda de gás natural. No ano de 2000, os transportes representavam $4 \%$ do consumo final de gás natural, já em 2005 esse valor era de 18\%.

Levando em conta o cenário de crescimento do país, projeção de reservas e intenções de investimentos da produção de gás natural, estima-se que em 2030 a produção pode chegar a 251,7 milhões de m3/dia com crescimento de $5 \%$ ano, enquanto que o consumo pode chegar a $4 \%$ ao ano.

\subsection{Hidroelétricas}

Percebe-se que, nas regiões mais desenvolvidas, boa parte do potencial hidráulico já foi aproveitada. No entanto, segundo o Plano Decenal de Expansão de Energia Elétrica 2006-2015, com o aproveitamento da bacia do Amazonas - nos locais onde acredita-se não possuir um impacto ambiental relevante - e das demais bacias, até um índice de $70 \%$, será possível suprir a crescente demanda até 2015.

Em 2030, estima-se um consumo de energia elétrica entre 950 e $1.250 \mathrm{TWh} / \mathrm{ano}$, sendo que o consumo atual situa-se em torno de 405 TWh. Essa diferença exigirá investimentos pesados na expansão da oferta de energia elétrica. No caso deste fornecimento ser realizado por usinas hidroelétricas, mesmo com uma instalação adicional de $120 \mathrm{GW}$, o que eleva para $80 \%$ o uso do potencial, ainda assim poderia não ser suficiente para atender a demanda em 2030.

\subsection{Energia Nuclear}

Uma das restrições na produção nacional de urânio é a capacidade de processamento que será em 2010 de 60\% da demanda total das Usinas Angra 1 e Angra 2. Com a entrada de Angra 3, prevista no plano Decenal de Expansão de Energia Elétrica 2006-2015, a demanda de urânio aumentará em torno de 110\%. Entretanto, mesmo com a expansão projetada das linhas de enriquecimento, a capacidade total continuará atendendo somente a $60 \%$ da necessidade de urânio. Se for levado em conta um cenário para custo de exploração de urânio entre U\$ 40/kg e U\$ 80/kg tem-se um potencial de 17500 MW em usinas para geração nuclear e a instalação de até 17 unidades.

\subsection{Outras Fontes de Energia}

Muitas das energias alternativas são destinadas a produção de energia elétrica. Existem muitos investimentos na área das energias renováveis devido a incentivos de governos além da preocupação com o meio ambiente.

A partir das Figuras 17 e 18, pode-se confirmar esse crescimento desses tipos de energia, que são as energias dos mares, a biomassa, a eólica, a solar entre outras, 
mas mesmo com esse crescimento essas energias não possuem grande expressão na matriz brasileira atual e na prevista para 2030.
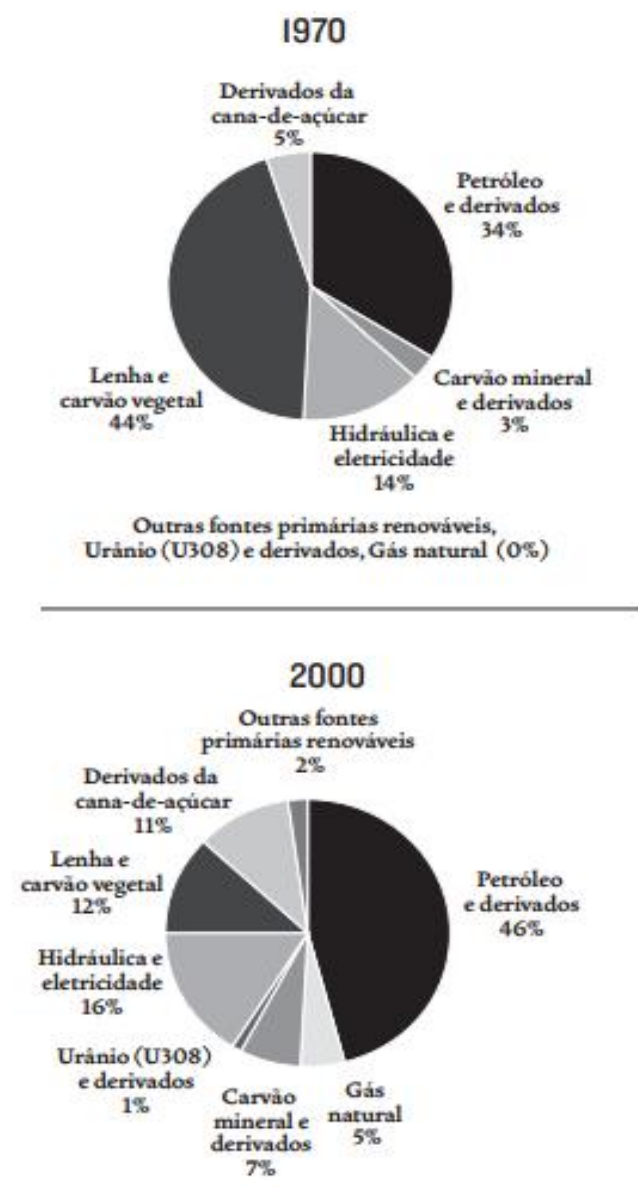

Figura 8: Projeção de produção de demanda de energia elétrica para outras fontes em 1970 e 2000.

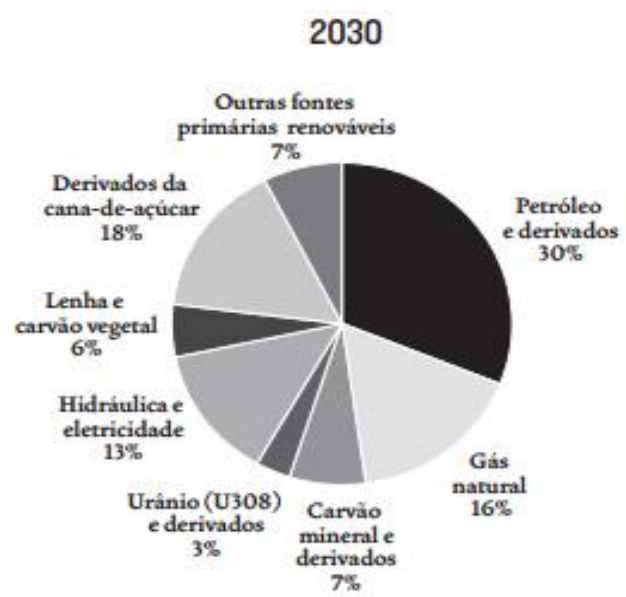

Figura 9: Projeção de produção de demanda de energia elétrica para outras fontes em 2030.

\section{Conclusão}

A matriz energética de um país é constantemente alterada de acordo com a necessidade e disponibilidade de recursos. Os contextos históricos, políticos e socioeconômicos também são fatores que devem ser levados em conta ao se fazer um estudo, ou até mesmo uma previsão sobre cenários energéticos em geral.

Posto, as mudanças na matriz energética podem ser ampla e claramente perceptíveis no Brasil se considerarmos as informações e acontecimentos provenientes de um determinado período histórico. O presente trabalho considerou dados da antiga matriz energética brasileira, a partir da década de 1980, pós crise do petróleo nos idos de 1970, e fez uma breve previsão, até o ano de 2030, sobre as principais fontes que deverão, ou pelo menos deveriam, compor o panorama energético nacional.

Assim, para realizarmos essa tarefa levamos em conta o potencial de geração, suas limitações, assim como sua disponibilidade. Por exemplo, no Brasil pôde-se perceber durante a década de 1970 o início de uma expressiva mudança em função do alto preço do petróleo. Esse fator contribuiu para um maior investimento em pesquisa visando novas alternativas.

Por fim, para que o país permaneça se desenvolvendo faz-se necessário que exista energia abundante disponível, a fim de suprir a demanda decorrente do crescimento. Nessa perspectiva, foi fundamental a formulação de um estudo que nos possibilitasse maior compreensão da futura configuração energética nacional. Nesse ponto, aparece o viés educacional deste trabalho. Entendemo-lo como um relatório de pesquisa para estudantes interessados em adquirir uma visão geral, panorâmica da situação energética brasileira, a partir dos anos de 1970.

\section{Agradecimentos}

Agradecemos ao Professor Rubens Martins Moreira do Centro de Desenvolvimento de Tecnologia Nuclear (CDTN) por nos receber e nos incentivar a defender e divulgar a energia nuclear.

Agradecemos ao Professor Alexandre C. Tort, do Instituto de Física da UFRJ , pelas correções, sugestões e paciência, com o nosso excesso de entusiasmo.

Agradecemos a Professora Socorro Lima Costa do Departamento de Ciências Biológicas por abraçar nosso projeto.

Agradecemos à FAPEMIG e ao CNPq, sem os quais esta pesquisa não poderia ser realizada.

Agradecemos ao Instituto de Ciência e Tecnologia (ICT) da UFVJM e a Pró-reitoria de Pesquisa e Pósgraduação da UFVJM pelo apoio logístico e confiança.

\section{Referências}


ANÁLISE ENERGÉTICA E DADOS AGREGADOS. Disponível em: <file:///C:/Users/Henrique/Desktop/ relatorio_pesquisa1.pdf $>$. Acesso em: 24 jun 2014.

CARLOS, L. Pensando gestão rural - e a situação energética no Brasil. Disponível em: <http:// lacarlosrevisoradeportugues.blogspot.com.br/2013/08/ pensando-gestao-rural-e-situacao.html >. Acesso em: 15 out 2014.

EMPRESA DE PESQUISA ENERGÉTICA - PARTE 1. Plano Nacional de Energia - PNE 2030. Disponível em: <https://ben.epe.gov.br/downloads/Relatorio_ Final_BEN_2013.pdf> Acesso em: 01 jun 2014.

EMPRESA DE PESQUISA ENERGÉTICA - PARTE 2. Plano Nacional de Energia - PNE 2030. Disponível em: $<$ http://pt.slideshare.net/renataecleverlan/a-produomundial-de-energia-e-as-fontes-de-energia-no-brasilparte-ii >. Acesso em: 04 jun 2014.

MINISTÉRIO DE MINAS E ENERGIA. Balanço energético Nacional 2013. Disponível em: <https://ben.epe.gov. br/downloads/Relatorio_Final_BEN_2013.pdf > Acesso em: 01 jun 2014

MINISTÉRIO DE MINAS E ENERGIA. Plano Nacional de Energia - PNE 2030. Brasília. 2007. Disponível em: $<$ https://ben.epe.gov.br/downloads/Relatorio_Final_ BEN_2013.pdf> Acesso em: 01 jun 2014.

TRACTEBEL ENERGIA. PNE 2050 será lançado ainda neste ano, diz MME. Disponível em: < http://www. tractebelenergia.com.br/wps/portal/internet/imprensa/ noticias/conteudos/pne-2050-sera-lancado-aindaneste-ano-diz-mme-101135>. Acesso em: 02 jul 2014. 